\title{
Editorial: A Golden Age for Strontium Isotope Research? Current Advances in Paleoecological and Archaeological Research
}

\author{
Kate Britton ${ }^{1,2 *}$, Brooke E. Crowley ${ }^{3,4}$, Clément P. Bataille ${ }^{5,6}$, Joshua H. Miller $^{3}$ and \\ Matthew J. Wooller ${ }^{7,8}$ \\ ${ }^{1}$ Department of Archaeology, University of Aberdeen, Aberdeen, United Kingdom, ${ }^{2}$ Department of Human Evolution, \\ Max-Planck-Institute for Evolutionary Anthropology, Leipzig, Germany, ${ }^{3}$ Department of Geology, University of Cincinnati, \\ Cincinnati, OH, United States, ${ }^{4}$ Department of Anthropology, University of Cincinnati, Cincinnati, OH, United States, \\ ${ }^{5}$ Department of Earth and Environmental Sciences, University of Ottawa, Ottawa, ON, Canada, ${ }^{6}$ Department of Biology, \\ University of Ottawa, Ottawa, ON, Canada, ${ }^{7}$ Alaska Stable Isotope Facility, University of Alaska Fairbanks, Fairbanks, AK, \\ United States, ${ }^{8}$ Department of Marine Biology, University of Alaska Fairbanks, Fairbanks, AK, United States
}

Keywords: mobility, provenance, migrations, landscape use, ${ }^{87} \mathrm{Sr} /{ }^{86} \mathrm{Sr}$

\section{Editorial on the Research Topic}

A Golden Age for Strontium Isotope Research? Current Advances in Paleoecological and Archaeological Research

\section{OPEN ACCESS}

Edited and reviewed by: Franco Biondi,

University of Nevada, United States

${ }^{*}$ Correspondence: Kate Britton

k.britton@abdn.ac.uk

Specialty section:

This article was submitted to

Paleoecology

a section of the journal

Frontiers in Ecology and Evolution

Received: 22 November 2021 Accepted: 21 December 2021

Published: 13 January 2022

Citation:

Britton K, Crowley BE, Bataille CP,

Miller JH and Wooller MJ (2022)

Editorial: A Golden Age for Strontium Isotope Research? Current Advances in Paleoecological and Archaeological

Research.

Front. Ecol. Evol. 9:820295. doi: 10.3389/fevo.2021.820295
Building from a session we chaired at the 2019 International Union for Quaternary Research Congress in Dublin, this Research Topic explores advances and new applications in strontium isotope research across paleoecology, archaeology, and allied fields. These contributions encompass the range of current research, the latest developments, and future potentials of this rapidly advancing research area. With authors from the fields of archaeology, anthropology, geology, geochemistry, and ecology, the multi-disciplinary relevance of modern strontium isotope analyses of biological materials is clear. The scope of the papers is also vast, with international research teams presenting work from Madagascar, the USA, Canada, the Peruvian and Southern Andes, China, the Levant, Western Europe and Scandinavia, and a temporal range spanning from the Neolithic up to the present.

Papers by Weber et al. and Snoeck et al. present novel experimental studies sensu stricto: A controlled feeding study using rodents, and the evaluation of artificially-treated wood samples, respectively. In their study, Weber et al. found differences in the time it took for cohorts of rats to reach tissue equilibrium after a dietary switch, as well as time-lags along the growth axis of their teeth. They also found inter-specific differences in equilibration time when individuals were fed new diets. There was a measurable influence of both drinking water and kaolin dust on rodent enamel, shifting enamel strontium isotope ratios $\left({ }^{87} \mathrm{Sr} /{ }^{86} \mathrm{Sr}\right)$ toward these additive sources. These authors go on to speculate that some diet-tissue ${ }^{87} \mathrm{Sr} /{ }^{86} \mathrm{Sr}$ differences may reflect bioavailable components of diet differing from bulk ${ }^{87} \mathrm{Sr} /{ }^{86} \mathrm{Sr}$-an idea supported by subsequent acid leaching tests on food samples designed to mimic the rodents' digestive tracts. These findings contribute significantly to our understanding of bioavailable ${ }^{87} \mathrm{Sr} /{ }^{86} \mathrm{Sr}$ assimilation and complement the few previous controlled feeding studies (e.g., Lewis et al., 2017; Anders et al., 2019).

Despite a small number of successful applications (e.g., English et al., 2001; Rich et al., 2016; Hajj et al., 2017), strontium-based wood provenance research in archaeology remains controversial. Archaeological wood is often either waterlogged or has been treated in some way, and the impact 
of these processes on ${ }^{87} \mathrm{Sr} /{ }^{86} \mathrm{Sr}$ has not been well-characterised. In their experimental study, Snoeck et al. artificially waterlogged wood in salt-water, or treated them with pitch, and found that these both altered wood ${ }^{87} \mathrm{Sr} /{ }^{86} \mathrm{Sr}$. The authors then explored the efficacy of various pre-treatments for removing this exogenous strontium, concluding that waterlogged samples may be unsuitable for ${ }^{87} \mathrm{Sr} /{ }^{86} \mathrm{Sr}$ analyses with any of the current pre-treatment protocols. Conversely, for pitch-treated samples, organic solvents proved effective in removing contaminants, but that aqueous-based acid-base-acid pre-treatment removed significant amounts of endogenous strontium as well. These findings underpin the need for continued caution in the use of ${ }^{87} \mathrm{Sr} /{ }^{86} \mathrm{Sr}$ in wood provenance studies, particularly in the case of waterlogged wood.

$\mathrm{Hu}$ et al. provide a useful field experimental dataset from the multi-isotope, intra-strand analysis of human hair from an individual with known (and considerable) movement history. They measured and compared carbon, hydrogen, and strontium isotopes with expected isotope profiles using the individual's travel history and existing databases of isotope values in human hair. They demonstrate that hydrogen and, to a lesser extent, carbon isotopes faithfully record expectations when the individual travelled to isotopically-distinct regions and for periods longer than a couple of weeks. Unfortunately, they also demonstrate that the ${ }^{87} \mathrm{Sr} /{ }^{86} \mathrm{Sr}$ profile for this individual's hair does not record travel history. Instead, it displays a constant ratio similar to the ${ }^{87} \mathrm{Sr} /{ }^{86} \mathrm{Sr}$ of the last location of residence. This finding corroborates previous laboratory experiments (e.g., Tipple et al., 2013; Hu et al., 2020) showing that strontium exchanges rapidly with water when wetted. This study underlines that more work is required to understand how strontium integrates in organic tissues, particularly those for which it is not a structural component and is only present in trace amounts (e.g., keratin, cellulose). In these tissues, contamination from exogenous sources can rapidly modify ${ }^{87} \mathrm{Sr} /{ }^{86} \mathrm{Sr}$ and complicate interpretations.

Many papers in this Research Topic revolve around the central issue of how we use underlying ${ }^{87} \mathrm{Sr} /{ }^{86} \mathrm{Sr}$ variability within landscapes to interpret mobility in the past, reflecting a current preoccupation of the field. In their contributions, both Andreasen and Thomsen and Thomsen et al. explored how anthropogenic activities can modify bioavailable ${ }^{87} \mathrm{Sr} /{ }^{86} \mathrm{Sr}$. Specifically, they investigated how widespread farming and agricultural liming can impact local bioavailable ${ }^{87} \mathrm{Sr} /{ }^{86} \mathrm{Sr}$, which in turn affects our ability to use modern isotope baselines in assessments of past human mobility. To assess the impacts of agricultural liming, Andreasen and Thomsen took advantage of a site in Denmark that was previously subjected to large additions of lime. Five years after liming, the authors analysed soil geochemistry to quantify the modification of strontium concentration and strontium mobility within the profile. They determined that strontium is highly mobile and estimate that after only 5 years, the majority of strontium added by the liming experiment had escaped the shallow soil profiles, likely flowing into the underlying groundwater. They further found that surface water at the experimental site has similar ${ }^{87} \mathrm{Sr} /{ }^{86} \mathrm{Sr}$ to agricultural lime (and lower than nearby surface waters). These findings suggest that agricultural liming has the potential to impact local strontium geochemistry, particularly in soils with naturally low strontium concentrations. They conclude that evaluating the ${ }^{87} \mathrm{Sr} /{ }^{86} \mathrm{Sr}$ of archaeological specimens using isoscapes (maps of environmental ${ }^{87} \mathrm{Sr} /{ }^{86} \mathrm{Sr}$ ) that incorporate agriculturally "contaminated" data will likely lead to overestimating the mobility of past human populations. However, in a commentary to this article, Frei (2021) caution that the mass balance calculations used by Andreasen and Thomsen do not account for the historical additions of strontium over the past century and that they subsequently overestimate the role of recent lime additions to the bioavailable ${ }^{87} \mathrm{Sr} /{ }^{86} \mathrm{Sr}$ pool.

Building on this theme, Thomsen et al. evaluated ${ }^{87} \mathrm{Sr} /{ }^{86} \mathrm{Sr}$ variability in Denmark both as a function of underlying Quaternary geology (different glacial tills) as well as agricultural activity. They show that the overall range of water ${ }^{87} \mathrm{Sr} /{ }^{86} \mathrm{Sr}$ in this region is higher than previous studies have suggested (e.g., Frei et al., 2019), and also that it varies across small geographical areas and geological boundaries. They also show that, within a region, surface waters from areas influenced by agricultural lime have lower ${ }^{87} \mathrm{Sr} /{ }^{86} \mathrm{Sr}$ than those from neighbouring areas without agricultural influence. In light of these findings, the authors reevaluate multiple Bronze and Viking age archaeological burials whose ${ }^{87} \mathrm{Sr} /{ }^{86} \mathrm{Sr}$ had been previously shown to be too high to be locally sourced. The authors conclude that, in light of their new data, the ${ }^{87} \mathrm{Sr} /{ }^{86} \mathrm{Sr}$ for many of these individuals and textiles is actually consistent with naturally occurring bioavailable ${ }^{87} \mathrm{Sr} /{ }^{86} \mathrm{Sr}$ within Denmark.

Other papers in this Research Topic address the different factors that influence bioavailability within landscapes and, ultimately, how these can shape and influence how we build isoscapes. This includes the generation of new and refined isoscapes from parts of South America and Europe. Barberena et al. and Scaffidi et al. both developed new isoscapes for different regions of South America-a continent apt for ${ }^{87} \mathrm{Sr} /{ }^{86} \mathrm{Sr}$-based geolocation studies given both its geological diversity and importance from an archaeological standpoint. Barberena et al. apply an existing mapping framework (Bataille et al., 2018, 2020) and combine machine learning and remote sensing data to generate bioavailable ${ }^{87} \mathrm{Sr} /{ }^{86} \mathrm{Sr}$ isoscapes for paleo-applications in the Southern Andes. The authors amassed a dataset of ${ }^{87} \mathrm{Sr} /{ }^{86} \mathrm{Sr}$ in plants and soils to calibrate a regional bioavailable ${ }^{87} \mathrm{Sr} /{ }^{86} \mathrm{Sr}$ isoscape. They used the calibrated isoscape for a preliminary archaeological study on human remains, where they argue for a pulse of migration in AD 1280-1420. This study emphasises the need to generate large bioavailable datasets for calibrating high-resolution regional bioavailable ${ }^{87} \mathrm{Sr} /{ }^{86} \mathrm{Sr}$ isoscapes.

Taking a different mapping approach, Scaffidi et al. used a large dataset of ${ }^{87} \mathrm{Sr} /{ }^{86} \mathrm{Sr}$ in water to calibrate a regional isoscape in South America. The use of water as a mapping substrate rather than plants or soils brings up some interesting questions that are also discussed in Frei (2021). While drinking water is not a dominant strontium source for osseous tissues in human (or other animals), water integrates strontium sources at a larger scale than soils and plants. As such, the authors speculate whether water might better represent the bioavailable ${ }^{87} \mathrm{Sr} /{ }^{86} \mathrm{Sr}$ that is available to humans because humans often consume food 
from regional sources. Using a kriging approach, Scaffidi et al. produce a robust map of ${ }^{87} \mathrm{Sr} /{ }^{86} \mathrm{Sr}$ in rivers and reiterate that the question of bioavailable substrate choice for archaeological study remains debated.

The study by Britton, et al. also focuses on isoscape reconstruction and the selection of substrate choice using an approach that compares ${ }^{87} \mathrm{Sr} /{ }^{86} \mathrm{Sr}$ signatures from soils, different plant types, and land snails in order to assess how much variation in estimations of environmental ${ }^{87} \mathrm{Sr} /{ }^{86} \mathrm{Sr}$ is introduced by the different materials researchers select. The study targets a region of south-west France and includes biological samples collected across 17 sampling locations spanning six lithological units. While the authors found a broad correspondence of plant and snail ${ }^{87} \mathrm{Sr} /{ }^{86} \mathrm{Sr}$ with lithological unit and previously-published soil ${ }^{87} \mathrm{Sr} /{ }^{86} \mathrm{Sr}$ data (Willmes et al., 2014, 2018), there is a closer relationship between plant and soil ${ }^{87} \mathrm{Sr} /{ }^{86} \mathrm{Sr}$ than between snails and soils. However, plants growing on heterogeneous substrates (e.g., granite) also had more variable ${ }^{87} \mathrm{Sr} /{ }^{86} \mathrm{Sr}$ than those on more homogeneous lithologies (e.g., limestone) echoing the findings of other ${ }^{87} \mathrm{Sr} /{ }^{86} \mathrm{Sr}$ bioavailability studies (e.g., Sillen et al., 1998; Hartman and Richards, 2014; Willmes et al., 2018; Aguzzoni et al., 2019). An influence of proximity to water on bioavailable ${ }^{87} \mathrm{Sr} /{ }^{86} \mathrm{Sr}$ was also determined, likely reflecting the origin of rivers on bedrocks with elevated ${ }^{87} \mathrm{Sr} /{ }^{86} \mathrm{Sr}$. These results highlight the importance of analysing biological samples to complement, inform and refine strontium isoscape models, and the authors outline practical recommendations for environmental sampling. The authors also discuss the potential for ${ }^{87} \mathrm{Sr} /{ }^{86} \mathrm{Sr}$ differences among plants with different rooting depths to be passed on to different herbivore guilds (e.g., grazers, browsers, and frugivores), emphasising the need for ongoing research into dietary selection and physiology on the ${ }^{87} \mathrm{Sr} /{ }^{86} \mathrm{Sr}$ of mineralized mammalian tissues.

Four papers in this Research Topic are dedicated to case studies, both archaeological (Tütken et al.; Wang et al.) and (paleo-)ecological (Crowley and Godfrey; Miller et al.). Tütken et al. used strontium and oxygen isotopes to identify the origin of marine fish teeth (sharks and seabream) from Iron Age deposits from the City of David in the Southern Levant. The authors generated novel baseline data for modern marine and freshwater fish from Egypt and Israel and compared these data to their archaeological samples. Isotope data for seabream were similar to the modern marine fish, indicating they may have originated from the Mediterranean Sea or the hypersaline Bardawil Lagoon, Egypt. However, isotope data for the shark teeth did not match the modern reference dataset and were more compatible with seawater during the Late Cretaceous. Additional analyses confirm a fossil origin, and several of the identifiable teeth belong to Cretaceous taxa. The authors propose that these teeth were brought to the city as a cultural commodity. This study is particularly significant because it demonstrates how dual isotope analysis can not only trace the geographical origins of animal foods exploited in the past but also distinguish contemporary and fossil specimens-making this distinction is critical for understanding human behaviour in the past.
In their archaeological study, Wang et al. re-analysed previously published tooth enamel ${ }^{87} \mathrm{Sr} /{ }^{86} \mathrm{Sr}$ for domestic fauna, including pigs, cows, sheep/goats, horses, and dogs from a range of Neolithic and Western Zhou Dynasty sites in China and used Bayesian methods to build an isoscape to explore differences in the movement of domestic fauna and/or their primary products among sites and through time. The authors determined a large diversity of origins for animals (particularly sheep and cattle) from the Late Neolithic onwards, and argue that these data demonstrate that wider circulation networks (evidenced by greater diversity in faunal strontium isotope ratios) replaced more local economies during this period. This study highlights both the potential for strontium isotope approaches to reveal social and economic changes through time, and the power of bringing together larger datasets from multiple sources.

In an ecological application, Crowley and Godfrey determined variability in ${ }^{87} \mathrm{Sr} /{ }^{86} \mathrm{Sr}$ for co-occurring extant and extinct lemur genera in Madagascar to test the hypothesis that extinct, large-bodied lemurs were relatively sedentary and had small home ranges similar to smaller-bodied still-extant lemurs. Low ${ }^{87} \mathrm{Sr} /{ }^{86} \mathrm{Sr}$ variability for all genera supports low mobility for extinct lemurs. The authors conclude that low metabolisms and activity levels appear to be shared traits within Lemuriformes that may have evolved in response to the harsh environments that characterise Madagascar. This paper highlights the interactions between paleobiology, strontium isotope geochemistry, and modern conservation ecology.

Miller et al. take advantage of the ecological and taphonomic opportunities of antler accumulations (Miller, 2012; Miller et al., 2013) in their historical ecology case study. Using antler ${ }^{87} \mathrm{Sr} /{ }^{86} \mathrm{Sr}$, they reconstruct historical migrations for two herds of North American caribou, the Central Arctic and Porcupine Caribou Herds, which currently calve on the Coastal Plain of the Arctic National Wildlife Refuge, Alaska (USA). The authors evaluated patterns of summer landscape use for both herds and found that while the Porcupine Herd show continuity in patterns of summer landscape use, the Central Arctic Herd indicate a shift in summer range after the late 1970s. This study highlights the detailed historical ecological data available from skeletal accumulations and the value of integrating historical perspectives into our evaluations of how animal populations are responding to modern environmental, climatic, and anthropogenic perturbations.

Finally, this Research Topic includes two perspective pieces on the past development and future directions of the field by Sillen and Britton et al. Sillen, a pioneer in the field, reviews the advent of ${ }^{87} \mathrm{Sr} /{ }^{86} \mathrm{Sr}$ analysis, both in terms of initial research into radioactive isotopes in the food chain in the 1960s, and the unintended consequence, the initial applications to ancient human and faunal remains. He also evaluates the current field and encourages the continued and ongoing development of the techniques themselves, arguing that fundamental studies, such as controlled feeding experiments, tissue formation and diagenesis research, modelling, and ecosystem mapping necessitate thoughtful funders as well as interdisciplinary teams. Britton et al. also reflect on the value of controlled feeding 
experiments and appraise important recent developments in computational modelling and isoscape mapping in the field. They too emphasise the strengths of cross-disciplinarity and multi-proxy approaches, calling for both theoretical as well as methodological innovation in the field. As highlighted by many of the papers in this Research Topic, these calls are beginning to be answered-we are truly now entering a golden age for strontium isotope research.

\section{AUTHOR CONTRIBUTIONS}

$\mathrm{KB}$ and $\mathrm{BC}$ planned out the editorial. $\mathrm{KB}$ wrote the initial draft with input from BC. All authors made written contributions, comments, and edits.

\section{REFERENCES}

Aguzzoni, A., Bassi, M., Robatscher, P., Scandellari, F., Tirler, W., and Tagliavini, M. (2019). Intra- and intertree variability of the $87 \mathrm{Sr} / 86 \mathrm{Sr}$ ratio in apple orchards and its correlation with the soil $87 \mathrm{Sr} / 86 \mathrm{Sr}$ ratio. J. Agric. Food Chem. 67, 5728-5735. doi: 10.1021/acs.jafc.9b01082

Anders, D., Osmanovic, A., and Vohberger, M. (2019). Intra- and inter-individual variability of stable strontium isotope ratios in hard and soft body tissues of pigs. Rap. Commun. Mass Spectromet. 33, 281-290. doi: 10.1002/rcm.8350

Bataille, C. P., Crowley, B. E., Wooller, M. J., and Bowen, G. J. (2020). Advances in global bioavailable strontium isoscapes. Palaeogeogr. Palaeoclimatol. Palaeoecol. 555:109849. doi: 10.1016/j.palaeo.2020.109849

Bataille, C. P., von Holstein, I. C. C., Laffoon, J. E., Willmes, M., Liu, X.-M., and Davies, G. R. (2018). A bioavailable strontium isoscape for Western Europe: a machine learning approach. PLOS ONE 13:e0197386. doi: 10.1371/journal.pone.0197386

English, N. B., Betancourt, J. L., Dean, J. S., and Quade, J. (2001). Strontium isotopes reveal distant sources of architectural timber in Chaco Canyon, New Mexico. Proc. Natl. Acad. Sci. U.S.A. 98, 11891-11896. doi: $10.1073 /$ pnas. 211305498

Frei, K. M., Bergerbrant, S., Sjögren, K.-G., Jørkov, M. L., Lynnerup, N., Harvig, L., et al. (2019). Mapping human mobility during the third and second millennia BC in present-day Denmark. PLOS ONE 14:e0219850. doi: 10.1371/journal.pone.0219850

Frei, R. (2021). Commentary: strontium is released rapidly from agricultural limeimplications for provenance and migration studies. Front. Ecol. Evol. 9:681896. doi: $10.3389 /$ fevo.2021.681896

Hajj, F., Poszwa, A., Bouchez, J., and Guérold, F. (2017). Radiogenic and "stable" strontium isotopes in provenance studies: a review and first results on archaeological wood from shipwrecks. J. Archaeol. Sci. 86, 24-49. doi: 10.1016/j.jas.2017.09.005

Hartman, G., and Richards, M. (2014). Mapping and defining sources of variability in bioavailable strontium isotope ratios in the Eastern Mediterranean. Geochim. Cosmochim. Acta 126, 250-264. doi: 10.1016/j.gca.2013.11.015

Hu, L., Fernandez, D. P., Cerling, T. E., and Tipple, B. J. (2020). Fast exchange of strontium between hair and ambient water: implication for isotopic analysis in provenance and forensic studies. PLoS ONE 15:e0233712. doi: 10.1371 /journal.pone. 0233712

Lewis, J., Pike, A. W. G., Coath, C. D., and Evershed, R. P. (2017). Strontium concentration, radiogenic $(87 \mathrm{Sr} / 86 \mathrm{Sr})$ and stable $(888 \mathrm{Sr}$ ) strontium isotope systematics in a controlled feeding study. STAR Sci. Technol. Archaeol. Res. 3, 45-57. doi: 10.1080/20548923.2017.1303124

Miller, J. H. (2012). Spatial fidelity of skeletal remains: elk wintering and calving grounds revealed by bones on the yellowstone landscape. Ecology 93, 2474-2482. doi: 10.1890/12-0272.1

\section{FUNDING}

KB thanks the Leverhulme Trust for support during the production of this editorial (PLP-2019-284).

\section{ACKNOWLEDGMENTS}

We thank everyone who contributed to this Research Topic. MW would like to acknowledge that, at Fairbanks, he is working on the ancestral land of Troth Yeddha, home of the Lower Tanana people. He would also like to acknowledge that the lands on which he does his work are the ancestral lands of the Dené people who stewarded those lands for thousands of years and continue to steward those lands, further he would like to thank them and respects their enduring relationship to their homelands.

Miller, J. H., Druckenmiller, P., and Bahn, V. (2013). Antlers on the Arctic Refuge: capturing multi-generational patterns of calving ground use from bones on the landscape. Proc. R. Soc. B 280:20130275. doi: 10.1098/rspb.2013.0275

Rich, S., Manning, S. W., Degryse, P., Vanhaecke, F., and Van Lerberghe, K. (2016). Provenancing East Mediterranean cedar wood with the 87 $\mathrm{Sr} / 86 \mathrm{Sr}$ strontium isotope ratio. Archaeol. Anthropol. Sci. 8, 467-476. doi: 10.1007/s12520-015-0242-7

Sillen, A., Hall, G., Richardson, S., and Armstrong, R. (1998). ${ }^{87} \mathrm{Sr} /{ }^{86} \mathrm{Sr}$ ratios in modern and fossil food-webs of the sterkfontein valley: implications for early hominid habitat preference. Geochim. Cosmochim. Acta 62, 2463-2478. doi: 10.1016/S0016-7037(98)00182-3

Tipple, B. J., Chau, T., Chesson, L. A., Fernandez, D. P., and Ehleringer, J. R. (2013). Isolation of strontium pools and isotope ratios in modern human hair. Anal. Chim. Acta 798, 64-73. doi: 10.1016/j.aca.2013.0 8.054

Willmes, M., Bataille, C. P., James, H. F., Moffat, I., McMorrow, L., Kinsley, L., et al. (2018). Mapping of bioavailable strontium isotope ratios in France for archaeological provenance studies. Appl. Geochem. 90, 75-86. doi: 10.1016/j.apgeochem.2017.1 2.025

Willmes, M., McMorrow, L., Kinsley, L., Armstrong, R., Aubert, M., Eggins, S., et al. (2014). The IRHUM (isotopic reconstruction of human migration) database - bioavailable strontium isotope ratios for geochemical fingerprinting in France. Earth Syst. Sci. Data 6, 117-122. doi: 10.5194/essd-6-1172014

Conflict of Interest: The authors declare that the research was conducted in the absence of any commercial or financial relationships that could be construed as a potential conflict of interest.

Publisher's Note: All claims expressed in this article are solely those of the authors and do not necessarily represent those of their affiliated organizations, or those of the publisher, the editors and the reviewers. Any product that may be evaluated in this article, or claim that may be made by its manufacturer, is not guaranteed or endorsed by the publisher.

Copyright (c) 2022 Britton, Crowley, Bataille, Miller and Wooller. This is an open-access article distributed under the terms of the Creative Commons Attribution License (CC BY). The use, distribution or reproduction in other forums is permitted, provided the original author(s) and the copyright owner(s) are credited and that the original publication in this journal is cited, in accordance with accepted academic practice. No use, distribution or reproduction is permitted which does not comply with these terms. 